\title{
Unruly bodies: resistance, (in)action and hysteresis in a public health intervention
}

\author{
Benjamin Hanckel ${ }^{1,2,3}$ D Sarah Milton ${ }^{1} \cdot$ Judith Green $^{1,4}$ (D)
}

Published online: 8 June 2020

(c) The Author(s) 2020

\begin{abstract}
Schools have long been sites of public health intervention on the bodies of children. Increasingly, these interventions also act on the bodies of educators. Our case study is an intervention focused on the future health of children's bodies ('The Daily Mile'), which, we argue, also resulted in the surveillance of educators' bodies. We draw on Bourdieu's concept of hysteresis to explore how those bodies can become 'unruly' during implementation, in both resisting and being positioned as reluctant. Hysteresis, an under-utilised Bourdieusian concept, proved useful for exploring embodiment at a point when there were mismatches between habitus and the changing field of primary education. We show how the non-participation of some actors (e.g. teachers) was positioned as part of a broader resistance to health as a dominant value, whereas non-participation of less-privileged social actors (e.g. Teaching Assistants) was problematised in different ways. We argue that attending to moments of hysteresis, in which the changing symbolic values of physical capital become explicit, surfaces not just how dominant discourses (e.g. healthism) become reproduced in fields, but also how they change and are resisted, and with what effects.
\end{abstract}

Keywords Bourdieu $\cdot$ Hysteresis $\cdot$ Education $\cdot$ Habitus $\cdot$ Field $\cdot$ Public health

Benjamin Hanckel

b.hanckel@westernsydney.edu.au

Sarah Milton

sarah.milton@kcl.ac.uk

Judith Green

j.m.green@exeter.ac.uk

1 King's College London, London, UK

2 Western Sydney University, EQ.1.04, South Parramatta Campus, Victoria Rd, Rydalmere 2150, Australia

3 University of Tasmania, Hobart, Australia

4 University of Exeter, Exeter, UK 


\section{Introduction}

The school is a key site of social reproduction; for Bourdieu, of 'producing the institutional conditions for the production of a habitus' (Bourdieu and Passeron 1990, p. 4). A long tradition of scholarship focuses on the ways in which schools act on and (re)shape the bodies of young people (Bourdieu and Passeron 1990; Foucault 1977). In Bourdieu's framing, the school also 'hides' its role in reproducing cultural structures and distinctions, such that the operation of power is not recognised. Increasingly, however, schools have also become the sites of explicit attempts to act on bodies through public health interventions (Fitzpatrick and Tinning 2014; Schee and Gard 2014) such as those designed to increase children's physical activity or change their diets. In implementing such interventions, some of the strategies of reproduction are revealed, and overtly opened up for scrutiny, reflection and debate. Interventions aim not to reproduce durable habitus, but rather to disrupt and change what are framed as 'unhealthy' dispositions. The case study we examine in this paper is one such example: 'The Daily Mile'. This scheme, which has been widely adopted by UK primary schools, requires class teachers to take students out of their classrooms to run for $15 \mathrm{~min}$ each day (equating to around a mile in length). The scheme is promoted by The Daily Mile Foundation, a non-profit organisation funded by INEOS, a multinational petrochemicals company. According to the Foundation website, The Daily Mile's aims are "to improve the physical, social, emotional and mental health and wellbeing of our children-regardless of age, ability or personal circumstances" (The Daily Mile Foundation 2019b). The scheme is also widely supported by local authority public health departments, including the one in our study area, which was encouraging all local primary schools to adopt The Daily Mile as part of a wider strategy to address an 'epidemic' of obesity (Hanckel et al. 2019). This, then, is an intervention overtly focused on children's bodies, through the daily repetition of an embodied practice (running) intended to act on the current (unhealthy, overweight) body to foster future physical capital, and to inculcate lifelong habits of daily physical activity. Educators, when mentioned on the supporting materials for the scheme, are only referred to as implementers: "No staff training is needed and there is no extra workload for teachers" (The Daily Mile Foundation 2019b). The explicit object of the intervention is the current and future body of the primary school child.

As Schee and Gard (2014) note, in the context of public schools in the US, there is nothing new in the use of schools as sites and instruments of public health. However, over recent decades, the field of education has been increasingly tied to what Crawford (1980) characterised as discourses of 'healthism': that is, those which frame health as the outcome of individual effort and discipline, and as a dominant value of society which can trump others. In the setting of this case study (London, UK), for instance, by October 2019 over 2,100 schools had registered to be part of an awards-based programme called 'Healthy Schools', administered by the Greater London Authority. Registered schools work towards a bronze, silver or gold award for the adoption of health activities 
that address 'health priorities' of the school, such as obesity; efforts which "will enable schools to directly support the health and wellbeing of their pupils and staff" (Greater London Authority 2019). The scheme is illustrative of the ways that schools are enrolled as sites for addressing public health priorities directed at both pupils and staff. The field of education has been, to an extent, colonised by a new field, that of public health, through strategies which institutionalise the production of particular kinds of healthy bodies (slim, fit) as not only a desirable and legitimate, but also a necessary, outcome of the school system.

The continuing resonance of discourses of healthism for young people and schools has been well rehearsed (Kirk and Colquhoun 1989; Lee and Macdonald 2010; Rich 2018). Kirk and Colquhoun (1989, p. 419) suggest these operate "mainly at regulating the size and shape of the body", and a body of scholarship attests to how this produces gendered, racialised and class-based bodies (Rich 2018; Vitus et al. 2018). Scholars have also documented the effects on the embodied practices of physical education teachers (Fisette 2015; González-Calvo et al. 2019; Sparkes 1999; Wrench and Garrett 2015). However, Schee and Gard (2014) argue that recent trends such as moral panics about obesity have intensified the focus on all educators, rather than just those responsible for teaching sport and physical education. Recent schools policy, they argue, has recruited a broader cadre of teachers: as role models; as 'instruments of policy compliance'; and (in a US context) as 'fiscal liabilities' for schools' health insurance programmes. There has, though, been little empirical research on the effects of public health interventions on the embodied practices of this wider body of educators.

Public health 'interventions' are deliberate points at which change is implemented. These are points at which the dispositions of educators can become out of sync, or 'ill-adjusted' to a shifting field (Bourdieu 1990, p. 62). To explore not just reproduction, but also resistance and change, we use Bourdieu's (1977, 1990, 2000) concept of hysteresis, or the hysteresis effect, as a tool to understand how (some) bodies can become 'unruly', and how this unruliness surfaces changes in the field of education, in which health interventions that require the surveillance of children's bodies and their healthy futures also lead to the surveillance of all bodies, as embodied practices are transformed throughout the school system.

\section{Habitus, embodiment, physical capital and hysteresis}

Bourdieu's work provides a useful lens to think through the impacts on educators of these changes in the field of education. Bourdieu (1977, p. 72) argues that individuals make sense of their place in the world through the habitus, which is the acquired "systems of durable, transposable dispositions" that give an individual a point of view, or position, in the world. Through "the internalisation of the structures of that world" (Bourdieu 1989, p. 18) the habitus shapes how the world is understood, and how bodies move through the world (Wacquant 1992, p. 18), such that "the body is in the social world but the social world is in the body" (Bourdieu 1990, p. 190). The world is made up of overlapping fields (e.g. sexual field, political field, education field), within which the habitus operates. Each field, for Bourdieu (1991, p. 215), 
is "a kind of arena in which people play a game which has certain rules", takenfor-granted truths about the world (doxa) (Bourdieu 1990), where access to certain types of capital within each field "commands access to the specific profits that are at stake in the field" (Bourdieu and Wacquant 1992, p. 97). When an agent's "habitus encounters a social world of which it is the product, it is like a "fish in water" (Bourdieu and Wacquant 1992, p. 127), such that the taken-for-granted truths of the world - the existing classificatory systems and power relations ${ }^{1}$ - are experienced as natural. When the habitus and the field do not align, however, a 'hysteresis effect' emerges, whereby an agent's dispositions persist, but are ill-adjusted to changing conditions.

Of interest in this study is the field of education and the embodied practices within this field, at a point in time when the diffusion of public health orientations render the physical health of children as an obligation. We are interested particularly in how this change in the field of education impacts on the distribution of physical capital (Shilling 2004, p. 474), that is, "the value placed upon the size, shape and appearance of the flesh". The accumulation of physical capital is important for its ability to be translated into other fields, and converted into additional resources, in the form of economic, cultural and/or social capital (Shilling 2004). The importance of physical capital, and its symbolic value, become, we argue, at stake for all bodies within the new field of public health-orientated school systems.

Disparities between dispositions in the habitus and conditions of the field can have significant psychic consequences for individuals dislocated at points of transition. Bourdieu $(1977,1990,1991,2000)$ refers to this phenomena as the hysteresis effect. Whilst limited in their number, several studies (Barrett 2018; Cant 2018; Kirschner and Lachicotte 2001; Roenn-Smidt et al. 2020) have used this concept in relation to health. Cant's (2018) study, for instance, draws on Bourdieu's work to explore the role of hysteresis in generating the rising prevalence of mental health disorder in undergraduates. Here, she suggests, there is a dislocation between students' dispositions and the new field of education. Dispositions are formed within a habitus where academic success is linked to meritocratic advance, and cultural and economic capital. However, the changing field of education, created from expanding access, rising student debt, and increased competition in a congested field, means students from lower social positions are unlikely to make the gains congruent with their habitus. The anxieties that result, she suggests, are effects of hysteresis: a state resulting from this dislocation.

The concept of hysteresis, or the hysteresis effect, is a present but often marginal concept throughout Bourdieu's (1977, 1990, 1991, 2000) writing. Hysteresis arises when a 'mismatch' and 'time lag' is encountered between the two "ontologically distinct but interrelated" (Hardy 2014, p. 128) concepts of habitus and field, where the former (the habitus) is out of sync with the latter (field). As Bourdieu explains:

\footnotetext{
1 Activist interventions often seek to surface and disrupt these taken-for-granted truths (see for instance: Hanckel, 2019).
} 
The presence of the past in this kind of false anticipation of the future performed by the habitus is, paradoxically, most clearly seen when the sense of the probable future is belied and when dispositions ill-adjusted to the objective chances because of a hysteresis effect are negatively sanctioned because the environment they actually encounter is too different from the one to which they are objectively adjusted. (Bourdieu, 1990: 62)

In these moments of asynchronicity, embodied practical beliefs no longer match the changed, or changing, context, which has shifted the way relationships and practices are organised.

Hysteresis has perhaps been under-utilised in the social sciences (Strand and Lizardo 2017). The few empirical applications include studies that have used the concept to make sense of social mobility (Friedman 2016), experiences of migration (Domaneschi 2018; Nowicka 2015), spinal cord injury (Barrett 2018), healthcare professionals' experiences of changing health care management (Kirschner and Lachicotte 2001, p. 454), and family care responsibilities in stroke rehabilitation in a transforming field of healthcare (Roenn-Smidt et al. 2020): these studies attest to the usefulness of the concept to reveal otherwise hidden tensions in fields. Cant (2018) further argues that hysteresis provides a way to bridge the social structural and psychological levels - in her example, the links between social class and mental health. Hysteresis is also one useful tool for addressing the critique of Bourdieu's work that it is insufficiently engaged with change, and how practices transform or evolve, and with what effects (Yang 2014). Focusing on the hysteresis in temporal shifts (whether changes in policy, in geographic/digital place/s, or in biological health) also allows us to 'capture' the habitus in motion, for two reasons. First, hysteresis can create unintended space/s for moments of reflexivity (Strand and Lizardo 2017), in that those things that normally 'go without saying' become notable, and as such are narrativised by practitioners within the field as they reflect on new discomforts (Nettleton and Green 2014), and/or moments of creativity created by mismatches (Domaneschi 2018, p. 502). Second, dispositions become more observable to scholarly investigation when visibly out of sync with the field (Costa et al. 2018; Costa and Murphy 2015), such as when actions previously congruent with a field become so mismatched that they are 'negatively sanctioned' (Bourdieu 1990, p. 62).

In this study, we put the concept of hysteresis to work to surface the tensions that arise as the field of public health expands into the field of education. Those professionals (teachers) who are expected to implement a public health intervention within the school find themselves not just adjusting to the intensifying imperatives of healthism, but also operating within a new field (public health) where their embodied dispositions come under increasing surveillance, and become potentially sanctioned as incongruent. Bodies therefore become sites of resistance, as physical capital circulates and changes value. 


\section{Methodology}

The study draws on data collected in 2018, in an ethnographic study undertaken (by the first author) across five schools in one London borough where The Daily Mile was being implemented. This is a diverse inner London borough, in which $29.6 \%$ of children live in income deprived households (Department for Communities and Local Government 2015). All schools in the study have majority black and minority ethnic (BAME) student populations, ranging from 63 to $90 \%$ of the student population, and between 10 and $25 \%$ of their children receive free school meals (a meanstested benefit).

The dataset includes health intervention documents and guidance available online; fieldnotes of participant observation of The Daily Mile in practice (49 Daily Miles, across 12 classes; 61 h of observation); 22 in-depth interviews; and 11 focus groups with 41 participants. As we have reported in detail elsewhere (Hanckel et al. $2019)$ the 63 interviews and focus group participants included children $(n=10$ interviewees; $n=35$ focus groups participants), teachers ( $n=3 ; n=9$ respectively), parents and carers ( $n=3$ focus group participants), and local public health practitioners ( $n=3$ interviewees). Interviews and focus groups were recorded and lasted for approximately 30-45 min in length. All participants self-selected to take part and provided their own and, where applicable, parent/guardian consent. The study had ethics approval from King's College London (approval numbers LRS-17/18-5510 \& LRS-17/18-6465). Our analysis here focuses on how those implementing the scheme narrate, and are narrativised within, the implementation.

\section{The role of the intervention: reframing schools as sites for health production}

In the interviews and focus groups, teachers articulated the incentives for adopting The Daily Mile as contributing to the school's reputation as a 'healthy school' and as actualising the school (and national) leaders' aspirations to contribute to the field of health. As Gail ${ }^{2}$ and Melissa report, when asked why the intervention was adopted:

lifelong healthy bodies, that's what you want, you know, we're at a time, we're in a generation where our children are going to sort of potentially die before their parents, it's horrendous the level of obesity and it's shocking actually, so we have to do something, as educators we have to do something. (Gail, School leader, ${ }^{3}$ School01).

the government wants us to address obesity in primary age children, and as a school we were seeing an increase in children [...] with very worrying weight problems, and they weren't really being addressed, although the

\footnotetext{
2 All names and identifying details have been changed.

3 'School leader' refers to head teachers, assistant head teachers, cohort coordinators and/or subject leads.
} 
school does have healthy lunch policies, we're a 'healthy school', we only allow fruit, we don't have tuck shops, but it wasn't enough. So we needed something else. (Melissa, School leader, School03)

Whilst the role of schools in health promotion has a long history, both the strength of obligation expressed here and the explicit espousal of the school's obligations as part of the public health field are perhaps striking. These extracts also reflect a theme common to most discussions with teachers: the elision of 'health' with anxiety about children's body weight. The emphasis on, and scrutiny of, body size and shape of children was perhaps most clearly articulated by Joni, who explained the visual assessments made by her and her colleagues at their school, which were used to justify adopting The Daily Mile:

we just sort of did a tally as the children came in[to the lunch room] of, in our opinion, visually, 'fine', 'a bit overweight', 'really overweight' and 'oh my goodness, you probably would count as obese'. We were very shocked by the numbers that we came up with. (Joni, School leader, School04)

Joni's reported shock at these observations of body size is important. These are children who have all been visible to the staff as pupils, but at the point of this intense physical surveillance, as they are categorised, ranked and quantified, they become hyper-visible as physical bodies and rendered as objects of potential intervention. In all schools in the study, this framing of body size as a problem to be addressed and the normalisation of the school as a legitimate site for mitigating obesity were presented as largely unquestionable. No interviewee suggested that the school's role should not include fostering the health of the students, and in all schools staff reported the efforts they made to address obesity. This typically entailed adopting a mix of interventions throughout the school day, of more or less formal kinds ('we only allow fruit'; 'afterschool football clubs'), which The Daily Mile becomes part of. Thus, the expectation (of school leaders) was that The Daily Mile would be incorporated into the health work that educators expect, and are expected, to do to ensure that children's embodied practices are directed toward a particular type of healthy body. This work is not just directed at children's current, often abjectly ('oh my goodness, really obese') embodied states, but also their (often class-based) dispositions: a concern legitimised through linkage to the risks of unhealthy futures. Eva and Ray reference these dispositions explicitly when outlining the rationales for adopting The Daily Mile:

I must admit I think [commitment to physical health] is sort of bred out from where we are catchment-wise in [name of borough] a lot of them [pupils] are not active [...]none of them do sports outside of school [...] or even, you know, active things. (Ray, School leader, School05)

[the goal is] just trying to keep children more active because there's loads of them, especially in this class, that just go home and sit in front of the TV and barely do stuff. So, it [The Daily Mile] is just something. We knew it would make everyone do something every day, because we see at lunchtimes some, like some of the girls in my class, just sit and not do anything, 
even though lunchtime obviously is like an active thing, there's loads of sports, there's loads of things available but they don't have to do it. (Eva, School leader, School01)

Thus, in the talk of our participants, the 'healthy school' is delineated from the field of 'home', where students' dispositions are shaped through an (inactive) habitus. More appropriate dispositions, better aligned to the healthy school, are evoked in Eva's contrast of The Daily Mile and 'lunchtimes', with the former as one with obligations towards particular kinds of activity, and the latter one in which sitting is not doing anything, and which activity is less regulated. Here, the particular disciplinary obligations of public health work are made explicit. This is echoed in a number of observations, where teachers distinguish The Daily Mile as purposeful, and as properly ordered, goal-orientated and disciplined:

She (teacher) asks them to get in a line, but as she does this, she says 'you are not out there to play' and 'you are not out there to wind each other up'. (Fieldnotes, School02, Class04)

I notice some children playing on the play equipment - this teacher gets annoyed with them if they are not following the circuit and moving. (Fieldnotes, School02, Class06)

Thus, implementing The Daily Mile becomes a strategy for embodying particular kinds of distinction: privileging practices that train the current body for a future (healthy, middle-class body) which will involve the allocation of specified times for purposeful and sustained physical activity, rather than frivolity or activity orientated to pleasure. Within the intervention, normative expectations about health work are thus inculcated: that it has to be regular, routinised, and also constituted through 'countable' moments, which are discursively and practically distinguished from 'play'. These expectations are materialised in the physical fabric of the school. In our observations we documented how playgrounds were amended with painted arrows, or with specially commissioned tracks designed for running, or had areas (e.g. the basketball court) that might have afforded different activities during playtime become designated as 'The Daily Mile area'. Across the field sites, we observed how play equipments, and often overuse of the drinking fountains, were activities that must be resisted to work on the healthy body for the duration of the mile. Expectations also materialised in new technologies such as publicly visible spreadsheets, which appear on school websites and classroom walls; the badges and trophies for those classrooms with the most accumulated miles; or the calculations and recording of individual classroom daily miles reported at whole school weekly assemblies. Some classes introduce wearable devices (e.g. Fitbits) to monitor heart rates of participating children. These provide teachable moments for science; but also training in the biological accomplishments that health requires, such as an elevated heart rate. As class teachers update the spreadsheets, count the miles, report their children's endeavours, and escort them physically to and from the sites for running, they, too, become visible as bodies: 
the expectation [is] that every class does it, so she [the headteacher] does monitor it and takes it very seriously and, you know, encourages all teachers to take their classes out. (Laura, Teacher, School01)

\section{The (un)healthy educator's body}

School leaders (head teachers; assistant head teachers; cohort coordinators; subject leads), those with a certain level of symbolic capital, were typically those who initiated the scheme, and presented the intervention to other educators in the school. They anticipated legitimate reluctance to adopt the intervention arising from concerns about fitting it into a busy school day: concerns related firmly to the field of education, and ones which were framed as easily addressed, within the existing conditions of an education field oriented to timetable and pedagogical objectives:

that's why I think if you have rotas [...] it has to work for the teacher flexibly in terms of their planning, and when they have to be able to judge when is the optimum for their class [...] if everyone's got ownership of it and they're flexible, and they're solution based and they're thinking, then it works. (Gail, School leader, School01)

Implicit in Gail's comments is the educator who accepts the intervention: (legitimate) barriers related to workload can be expected, but overcome if teachers are treated as professionals with control over the class timetable. This kind of legitimate reluctance, embedded in the assumed professional dispositions of teachers, is also anticipated in The Daily Mile guidance, where, under the 'Frequently Asked Questions', advice is given on addressing resistance:

Question: If a colleague is reluctant, how can I encourage them to start The Daily Mile?

Answer: The Daily Mile doesn't increase teacher workload, nor does it require specialist skills or training-it's as simple as opening the classroom door. Try piloting The Daily Mile with one or two keen members of staff, to lead the way for its introduction to the whole school. The feedback from teachers already doing The Daily Mile is very positive and they have embraced it readily as they see the positive impact it has on the children's health, happiness, learning and behaviour.

(The Daily Mile Foundation, 2019a)

The 'reluctant' teacher just needs to see that it works and recognise the impact on learning and health; these should surely trump other concerns.

However, if workload reservations were signalled as legitimate, others were not. Particularly challenging were resistances to the planned intervention that suggested a less than wholehearted or earnest commitment to the public health project:

We had some rather interesting conversations in the staff room, somebody wanted to call it 'The Daily Death' and we were like 'no, that's not positive 
is it, that's not really in the spirit of what we're doing here...' (Joni, School leader, School04)

As a school leader, Joni's work is to curtail such (even joking) undercutting of the dominance of health as a value. Recruiting teachers as a collective body is important, and expectations are set that all educators willingly undertake public health work, as part of their role as teachers. Training for health, through the regular practice of The Daily Mile, becomes explicitly aligned as a responsibility with the same status as any other pedagogical aim, as suggested in Erica's equation of physical exercise and 'maths and English'-one echoed in many other interviews in the dataset:

I think if we, in an ideal world, it would be every class doing a 15-minute group physical exercise and I think that would, and that would happen every day. I think that would be ideal, that every class, every day, that's part of our day. It would be the same as doing maths or the same as doing English, it happens every day with no reason for it not to happen. (Erica, School Leader, School04)

Indeed this vision is ultimately one where health is so dominant it moves from the hyper visibility of the implementation of The Daily Mile to disappearing as a takenfor-granted obligation of the school system:

...it becomes [ideally in the future] almost part of the day, like any other lesson. You know, this is Daily Mile time, you timetable it in at the start of the year, you know, this is when we're going to do it and it sort of happens, it just becomes...part of the school day. (Ray, School leader, School05)

I'm convinced enough to harbour the dream that in 10 years' time or less all children will run a mile a day as part of, you know, as part of going to school, it's as much a part of going to school as having a lunch at school, you know. It's more embedded within the infrastructure of a school than the actual curriculum itself, you know. (Michael, Public Health Practitioner)

In transforming the field towards this vision, Kylie, a School leader, explains the role of leaders in enrolling others to align with these new conditions. Using strategies of disciplinary power, they must overcome reluctance to the point where Laura's head teacher's (above) monitoring is no longer needed, and resistant bodies come to want to conform, as they come to understand that the intervention is for them as well as their pupils:

Ideally I'd want every class doing it every day unless there was something drastic going on. But I just need to work out how to get over the resistance from some teachers and what I don't want to do is have to push them into it all the time. I want them to do it because they see the benefits for the children and for themselves. (Kylie, School leader, School02)

Ideally, then, teachers do not simply escort their children to the activity, but also model it in an embodied way, by moving around the circuit. Although The Daily 
Mile website and materials do not require class teachers to run with their children, most in our case study did, and were expected to do so, as Kylie indicates:

I can't always be bothered to go and say, when I see it [staff not running] happening outside to go and say 'you should be running with your class'. And the thing is even if they don't run it doesn't matter, they could walk. (Kylie, School leader, School02)

Accompanying the children makes visible the teacher's walking or running body, just as standing still whilst supervising a class running around a playground renders the teacher's body as visible in its very stationary aspect, as two children in a focus group (School04) discuss in relation to a past teacher:

Axel: when your teacher doesn't run, yeah, it might not be fair, then why are we running, when she's like, she's like waiting for us to finish running around and but why is she not running? [...]

Albert: She just stood there.

Axel: She just stood there and talked.

Across the classes observed, only one teacher stood still, whilst providing directions to students, during The Daily Mile. It is notable that this teacher was also one of main implementers of The Daily Mile in their school, as well as the physical education lead: such unquestioned levels of physical and symbolic capital within the field protected them from disapproval. As another School leader put it, teachers were expected to literally embody being 'good role model[s]' (Kirsty, School leader, School01) for all the children.

\section{Unruly bodies: gendered, aged \& classed resistances}

Colleagues who continued to be reluctant to undertake The Daily Mile were framed as resisting not just the intervention, but resisting health itself. A typical positioning of the reluctant teacher focused on failures of disposition, embodied in a 'lazy' body. Within the new field, these bodies were unruly, lacking the privileged dispositions to care enough or to enjoy the right kinds of activity:

I think it's a mindset, because one of the few teachers I had [...] who had that reluctance and whatever [...] it was just a mindset, I think she was just lazy to be honest, you know, if I'm honest about it, she was just lazy and couldn't be bothered [...] maybe she just didn't like physical exercise. (Gail, School leader, School01)

I think some teachers are just a bit lazy and can't be bothered to do it! (Kylie, School leader, School02)

The shape and size of these lazy and 'unbothered' bodies also came under scrutiny, as lacking the physical capital required within the new public health field: 
if they [teachers] are overweight and they're sensitive about that, they don't like addressing the issue of weight in the school [...One] member of staff wasn't taking it up because she doesn't see the point, and she personally doesn't value physical activity and this initiative as being crucial to sowing the seeds to good health for kids, and that kind of reflects in her personal behaviours as well. (Vera, Public Health Practitioner)

Just as preparations for the Daily Mile had brought children's bodies into sharp focus, implementation now brought those of all teachers centre stage. A resistant or 'unruly body' emerges, which does not seek to actively move students because they themselves do not value physical capital, because of their body shape, their dispositions (being 'lazy'), and/or their habits (not liking 'physical exercise'). These unruly bodies become sites for violating the 'natural regularities' of a field that has come to value the embodiment of certain form/s of physical capital. It is in these moments of resistance, where an intervention about the surveillance of children's bodies surfaces tensions, that the broader surveillance of all bodies within the field of education becomes visible.

Resistances also make visible social relations within the field, particularly those of intersections between gender, age and class. Male teachers' bodies are often discussed in relation to competition and 'success', in examples such as the male teacher who enjoys physical activity and was "really militant about doing it" (Kylie, School leader, School02) such that the class performed well, or the two male teachers who "had both become very competitive with the kids in their class, so there was this whole sort of male competition thing going on" (Joni, School leader, School04). In contrast, the unruly educator's body, when it emerges, is always female-'her body' and 'she doesn't see the point'. This (female) gendered habitus intersects with that of ageing, with the dispositions of the ageing female body most notably out of sync with the new field:

so one of the teachers that was particularly adamant she wasn't going to do it, she's retired, it was her last, she was coming up to retirement, she wasn't very fit, you know, and she was just concerned I think that people were going to start making her wear Lycra and run round and round the playground, you know. (Joni, School leader, School04)

we've got quite a mature set of ladies as TAs[Teaching Assistants], which are fantastic, they're brilliant, we love them, but [...] there are quite a few that are, you know, over 55, you know? (Damien, Teacher, School04)

Damien's 'You know?' attends to tacit assumptions about the incapacity of bodies, and the (im)possibilities of the ageing female body to align well with the new focus on physical health. The imperatives to move away from this (now outdated) female ageing habitus are highlighted in narratives of achieving the correct dispositions:

I mean my [colleague] who's well into her 40s [...] if you see her she whizzes around every day, she's like a bullet. So it's about mindset [...] if you're older and there are physical, but as I said about myself, you know, I've got a knee 
problem at the moment but I'll do it at my pace because you still should be walking. (Gail, School leader, School01)

Thus narratives of resistance to the intervention can be redemptive: stories of changing hexis, as bodies and dispositions adjust to the new field. One interviewee, for instance, cites her own (lack of) physical capital to emphasise the possibility that all bodies can and should conform:

for the benefit of the tape I'm on the large side so I say 'well if I can do it, you can do it, come on, let's do one more lap together', and at the end of it I'm also [Interviewee breathes heavily] so that kind of works quite well! (Joni, School leader, School04)

Celebratory narratives position those who move beyond resisting as bodies who gradually align habitus with the field:

Yeah, I think, I know, one teacher in particular [...] she's not particularly sporty herself but she's out there and doing it and that's, and yeah, it's growing on her as well. I think there was a little bit of reluctance, not reluctance, just thinking how it could work in [but] now it's just part and parcel of her thing as well. (Kirsty, School leader, School01)

The celebration of resistance overcome and the visible aligning of habitus with field also makes visible the 'negative symbolic capital' that gets marked on the body by the initial resistance, remembered and retained by colleagues. The time lag between habitus and field may have been resolved, but it is not forgotten, in this marking of her 'reluctance' as attributed to a lack of disposition towards sport and exercise.

Cutting across the gendered and age based social positions in the field were those of class and ethnicity. Typically, unlike their pupils, qualified teachers in inner London are White British (around $85 \%$ of class teachers, and $93 \%$ of heads (Haque 2017)), and live outside the school's catchment area, whereas Teaching Assistants ('support staff') (almost all female) are more likely to be older, reside locally and come from BAME communities (Bach et al. 2006). If teachers are modelling bourgeois practices (regular and purposeful physical activity) to their pupils, who are positioned as having dispositions framed in the very different class habitus of their homes, Teaching Assistants are in an anomalous position. Unlike class teachers, they are likely to share social positions in the field of 'home' with the pupils, but in school they are also educators, charged with modelling new dispositions. One narrative resolution to this discrepancy was to reference another field - that of dieting and 'keep fit' - more aligned to the lower-class habitus of the Teaching Assistants, but nonetheless one that could mesh with the field of the healthy school with fewer risks of hysteresis:

But I have to say even with my support staff, at first because they were carrying around a bit of weight, but then they've done Weight Watchers a lot of them and now some of them do the Daily Mile twice a day, they're fitting it in with their healthy bit, you know, and they've all got their little Fitbits on, and they'll say to me, 'Oh yeah, I went out with that class, I'm going out 
again this afternoon', so it fits into them, and they're wanting to lose weight.

(Gail, School leader, School01)

Again, this is a celebratory narrative about taking active steps to foster physical capital and meet the requirements of the field. Although it is a positive appraisal of the Teaching Assistants' commitment, it also reproduces the social distinctions that position them in the field by evoking a correspondence between the oppositions of Teaching Assistant/teacher with dieting/ 'health'. If some Teaching Assistants were (overtly at least) celebrated for their involvement, more typically they resisted by simply not participating:

We come back in the classroom and the Teaching Assistant is there (a black female), main teacher is a white male. She says 'oh, you did the run with them?' - I say 'yes'. It is clear the teaching assistant does not run with them. (Fieldnotes, School04, Class08)

When teachers took the children out to run, some Teaching Assistants would stay to work in the classroom, sorting out displays or materials, and others would withdraw to the staff room whist the teacher went out with the class:

I speak to the two teaching assistants who discuss their Christmas and New Year plans [...], then I say 'I have to go downstairs and see if they are ready for the mile', the teaching assistants say 'enjoy'. They have no intention of joining. (Fieldnotes, School03, Class03)

[in the staffroom] several teaching assistants are sat around a table talking, drinking tea/coffee and eating biscuits [...] The Daily Mile is about to take place outside. They smile. I leave them sitting around the table and join The Daily Mile with the class. They do not join. (Fieldnotes, Class01, School01)

The public health intervention routinely brings into sharp focus the bodies of teachers (whether standing, running, fat, lazy or concerned about wearing Lycra), expected to embody the new obligations of public health. The Teaching Assistants' bodies remain, however, largely invisible: unless 'exceptional' in their resistance to their assumed habitus (gendered, age-appropriate and implicitly class-appropriate). Thus, as the field of public health enters that of education, new expectations settle on teachers: that as professionals they will embody new dispositions encapsulated in The Daily Mile, and model purposeful, regulated and countable physical activity orientated to achieving a 'healthy' (slim, fit) body for their students. These expectations lie differently on the Teaching Assistants. Positioned as less advantaged within the field of education, their bodies are simultaneously associated with the habitus of pupils' home fields as well as that of the new public health-oriented school system. As such, their resistance can be ignored rather than sanctioned: their withdrawal simply reinforces the subordinate position of those dispositions that no longer align with the new field. 


\section{Discussion}

This study has shown how the implementation of a popular health intervention surfaces tensions, as schools shift from being sites for public health interventions on the bodies of children, to fields of public health as well as education, in which educators are expected to become public health practitioners and role models. These new expectations get incorporated into the framing and (im)possibilities of all educators' embodied practices. The size and shape of the teacher's body becomes topicalised, as practitioners navigate overlapping habitus (gendered, ethnic, aged, social class) within a shifting field. We have drawn on Bourdieu's $(1977,1990,1991,2000)$ use of the concept of hysteresis, to surface moments of mismatch and time lag between dispositions, embodied (un)healthy practices, and how they get problematised as one transformation occurred in schools in London.

Public health interventions are useful moments to see habitus in action. They are examples of 'explicit pedagogy' (Bourdieu and Passeron 1990), which Yang (2014, p. 1533) argues can be seen in real-world contexts in the strategic calculations required in acquiring new skills and knowledge, 'and even a new form of habitus'. We see this here when educators strategically consider not just what must be taught, but also how the habitus must be shifted. As changes are planned and managed, insiders in the field are reflexive about practice, as they navigate their own and others' discomforts. The hysteresis effect surfaces through the intervention, which illuminates a change in the value of physical capital in the field of education. Non-participation of educators, those responsible for implementing the intervention, is labelled as resistance, and typically becomes related to the stock of physical capital they possess. Hysteresis is thus captured as moments of (in)action. As the field shifts to incorporate the imperative of health for all educators throughout the school day, the 'unruly body' emerges. Participation (or not) is observed, and bodies become classified as either positive and compliant, or alternatively as pathological to the intervention: the 'lazy' body, the 'overweight' body, the individual who has not embodied a disposition to the right kind of regular, health-orientated physical activity. The non-participating body is thus positioned not as resisting the intervention, but as resisting health itself. As these unruly bodies start to conform, overcoming the limitations of physical capital (the 'less sporty' body) is celebrated, in explicit moments of reflexivity on the changing habitus of the field.

These changes to the field of primary school education are of course taking place within a wider remodelling of education in the UK (and in many other countries), in which teachers (like professionals in other public sector fields) have, over the last two decades, come under increasing pressures from the intensification of workloads, metrification and managerial control (Carter and Stevenson 2012). In the UK, the growing number of Teaching Assistants in primary school classrooms is part of this remodelling (Bach et al. 2006), with most teachers working with at least one assistant within their classrooms. Health interventions enter, then, a field which is already adjusting to new relations between social actors, with teachers having to distinguish themselves as 'professionals' from a 
cadre of less qualified, and (typically) less socially advantaged actors. The differing ways that the resistant bodies of teachers and Teaching Assistants were narrativised in our study surfaces not just the work that educational fields do in structuring gendered and ageing habitus (work that might otherwise be invisible), but also in structuring social class distinctions. Teachers must conform: in the new field, maintaining their professional distinction from the pupil body relies on physically modelling bourgeois health practices, often distinguished from the 'unhealthy' (inactive) habitus of home environments. The Daily Mile perhaps provides an exemplary opportunity for this regular, ordered, purposeful activity, orientated to healthy futures, and clearly demarcated from other physical activities (unstructured play) and from less-privileged practices (watching television, sitting). Teaching Assistants-more likely to share the class positions of their pupils - are subject to fewer obligations of this sort. They can resist with fewer sanctions: their non-participation simply a reminder of the inactive lower-class body. When they are enrolled, another habitus is engaged: a more class-congruent one of 'dieting', and the narratives are particularly celebratory, given the gap between their primary habitus (ageing, gendered, class-based) and the new conditions of the field.

That the school has a role in shaping the bodies of children is not new. What this case study has caught, however, is a moment where particular kinds of public health projects are incorporated as an obligation of the primary school educator, whose own body, as well as that of the child, moves centre stage in the new field. As the public health intervention unfolds, there is a disjuncture between habitus and field. We have used the concept of hysteresis to explore the (im)possibilities of embodied practices at this point of change, as certain bodies become unruly. Attending to hysteresis brings into focus changes in the field and makes visible the workings of habitus.

Acknowledgements A working version of this paper was presented at the British Sociological Association's Medical Sociology Conference. We thank the conference organisers for providing us with space to present this material, and the feedback we received from those in attendance. We also thank the Lewisham Department of Public Health staff who participated in the study. We are particularly grateful to the staff and children in participating schools in Lewisham, who were generous with their time and knowledge, and willing to share their Daily Miles.

Funding This study was funded by the UK Medical Research Council (MRC), through grant MR/ R014094/1 "Developing a theory of change, outcome measures and evaluation design for an evaluation of the impact of the Daily Mile on obesity and health". The funding sources played no role in study design, collection, analysis or interpretation of data, or writing of the manuscript.

Availability of data and materials The datasets generated and/or analysed during the current study are not publicly available due to ongoing analysis (qualitative data) or confidentiality (Lewisham data). Anonymised interview transcripts will be deposited in due course, and will be available from the corresponding author upon reasonable request.

Open Access This article is licensed under a Creative Commons Attribution 4.0 International License, which permits use, sharing, adaptation, distribution and reproduction in any medium or format, as long as you give appropriate credit to the original author(s) and the source, provide a link to the Creative Commons licence, and indicate if changes were made. The images or other third party material in this article are included in the article's Creative Commons licence, unless indicated otherwise in a credit line to the 
material. If material is not included in the article's Creative Commons licence and your intended use is not permitted by statutory regulation or exceeds the permitted use, you will need to obtain permission directly from the copyright holder. To view a copy of this licence, visit http://creativecommons.org/licen ses/by/4.0/.

\section{References}

Bach, S., I. Kessler, and P. Heron. 2006. Changing job boundaries and workforce reform: the case of teaching assistants. Industrial Relations Journal 37 (1): 2-21. https://doi.org/10.111 1/j.1468-2338.2006.00387.x.

Barrett, T. 2018. Bourdieu, Hysteresis, and Shame: Spinal Cord Injury and the Gendered Habitus. Men and Masculinities 21 (1): 35-55. https://doi.org/10.1177/1097184X16652658.

Bourdieu, P. 1977. Outline of a theory of practice, 1st ed. Cambridge: Cambridge University Press.

Bourdieu, P. 1989. Social space and symbolic power. Sociological Theory 7 (1): 14-25.

Bourdieu, P. 1990. The Logic of Practice. Stanford: Stanford University Press.

Bourdieu, P. 1991. Language and symbolic power. Cambridge: Polity Press.

Bourdieu, P. 2000. Pascalian meditations. Stanford: Polity Press.

Bourdieu, P., and J. Passeron. 1990. Reproduction in Education, Society and Culture, 2nd ed. London: SAGE Publications Ltd.

Bourdieu, P., and L.J.D. Wacquant. 1992. An invitation to reflexive sociology. Chicago: University of Chicago Press.

Cant, S. 2018. Hysteresis, social congestion and debt: towards a sociology of mental health disorders in undergraduates. Social Theory \& Health 16 (4): 311-325. https://doi.org/10.1057/s4128 5-017-0057-y.

Carter, B., and H. Stevenson. 2012. Teachers, workforce remodelling and the challenge to labour process analysis. Work, Employment and Society 26 (3): 481-496. https://doi.org/10.1177/09500 17012438579.

Costa, C., and M. Murphy. 2015. Bourdieu, habitus and social research: the art of application, 1 st ed. Basingstoke: AIAA.

Costa, C., C. Burke, and M. Murphy. 2018. Capturing habitus: theory, method and reflexivity. International Journal of Research \& Method in Education. https://doi.org/10.1080/17437 27X.2017.1420771.

Crawford, R. 1980. Healthism and the medicalization of everyday life. International Journal of Health Services 10 (3): 365-388. https://doi.org/10.2190/3H2H-3XJN-3KAY-G9NY.

Department for Communities and Local Government. 2015. The English Indices of Deprivation. https://assets.publishing.service.gov.uk/government/uploads/system/uploads/attachment_data/ file/465791/English_Indices_of_Deprivation_2015_-_Statistical_Release.pdf.

Domaneschi, L. 2018. Brand new consumers: a social practice approach to young immigrants coping with material culture in Italy. Cultural Sociology 12 (4): 499-517. https://doi.org/10.1177/17499 75518768978 .

Fisette, J.L. 2015. The stigmatized physical educator. Qualitative Research in Sport, Exercise and Health 7 (4): 466-487. https://doi.org/10.1080/2159676X.2014.981574.

Fitzpatrick, K., and R. Tinning. 2014. Health education's fascist tendencies: a cautionary exposition. Critical Public Health 24 (2): 132-142. https://doi.org/10.1080/09581596.2013.836590.

Foucault, M. 1977. Discipline and punish: the Birth of the prison. Harmondsworth: Penguin.

Friedman, S. 2016. Habitus clivé and the emotional imprint of social mobility. The Sociological Review 64 (1): 129-147. https://doi.org/10.1111/1467-954X.12280.

González-Calvo, G., V. Varea, and L. Martínez-Álvarez. 2019. Health and body tensions and expectations for pre-service physical education teachers in Spain. Sport, Education and Society 24 (2): 158-167. https://doi.org/10.1080/13573322.2017.1331426.

Greater London Authority. 2019. Healthy Schools London: Why it is important. https://www.londo n.gov.uk/what-we-do/health/healthy-schools-london/awards/about/why-it-important. Accessed 10 Oct 2019. 
Hanckel, B. 2019. "I want my story to be heard...": Examining the production of digital stories by queer youth in East and South-East Asia. In: The geographies of digital sexuality. Palgrave Macmillan, Singapore, pp. 203-223. https://doi.org/10.1007/978-981-13-6876-9_11.

Hanckel, B., D. Ruta, G. Scott, et al. 2019. The Daily Mile as a public health intervention: a rapid ethnographic assessment of uptake and implementation in South London, UK. BMC Public Health 19 (1): 1167. https://doi.org/10.1186/s12889-019-7511-9.

Haque, Z. 2017. Visible Minorities, Invisible Teachers: BME Teachers in the Education System in England. Runnymede Trust and NASUWT.

Hardy, C. 2014. Hysteresis. In Pierre Bourdieu: Key concepts, ed. M. Grenfell, 126-146. New York: Routledge.

Kirk, D., and D. Colquhoun. 1989. Healthism and Physical Education. British Journal of Sociology of Education 10 (4): 417-434. https://doi.org/10.1080/0142569890100403.

Kirschner, S.R., and W.S. Lachicotte. 2001. Managing managed care: habitus, hysteresis and the end(s) of psychotherapy. Culture, Medicine and Psychiatry 25 (4): 441-456. https://doi. org/10.1023/A:1013068803396.

Lee, J., and D. Macdonald. 2010. 'Are they just checking our obesity or what?' The healthism discourse and rural young women. Sport, Education and Society 15 (2): 203-219. https://doi. org/10.1080/13573321003683851.

Nettleton, S., and J. Green. 2014. Thinking about changing mobility practices: how a social practice approach can help. Sociology of Health \& Illness 36 (2): 239-251. https://doi.org/10.1111/14679566.12101.

Nowicka, M. 2015. Bourdieu's theory of practice in the study of cultural encounters and transnational transfers in migration. MMG Working Paper 15-01. Göttingen: Max Planck Institute for the Study of Religious and Ethnic Diversity.

Rich, E. 2018. Gender, health and physical activity in the digital age: between postfeminism and pedagogical possibilities. Sport, Education and Society 23 (8): 736-747. https://doi.org/10.1080/13573 322.2018.1497593.

Roenn-Smidt, H., J.K. Shim, K. Larsen, et al. 2020. Hysteresis - or the mismatch of expectations and possibilities among relatives in a transforming health care system. Health Sociology Review 29(1). Taylor \& Francis: 31-44. https://doi.org/10.1080/14461242.2019.1704425.

Schee, C.V., and M. Gard. 2014. Healthy, happy and ready to teach, or why kids can't learn from fat teachers: the discursive politics of school reform and teacher health. Critical Public Health 24 (2): 210-225. https://doi.org/10.1080/09581596.2013.828152.

Shilling, C. 2004. Physical capital and situated action: a new direction for corporeal sociology. British Journal of Sociology of Education 25 (4): 473-487. https://doi.org/10.1080/0142569042000236961.

Sparkes, A. 1999. Understanding physical education teachers: a focus on the lived body. Learning and Teaching in Physical Education, 171-187. London: Falmer Press.

Strand, M., and O. Lizardo. 2017. The hysteresis effect: theorizing mismatch in action. Journal for the Theory of Social Behaviour 47 (2): 164-194. https://doi.org/10.1111/jtsb.12117.

The Daily Mile Foundation. 2019a. The Daily Mile: Frequently Asked Questions. Available at: https:// thedailymile.co.uk/faq/. Accessed 10 Oct 2019.

The Daily Mile Foundation. 2019b. The Daily Mile UK. Available at: https://thedailymile.co.uk/about/. Accessed 10 Oct 2019.

Vitus, K., M.K. Tørslev, K. Ditlevsen, et al. 2018. Body weight management and dilemmas of health responsibility for vulnerable groups in the changing Danish welfare state: a comparative case analysis. Critical Public Health 28 (1): 22-34. https://doi.org/10.1080/09581596.2017.1286294.

Wacquant, L. 1992. The structure and logic of Bourdieu's sociology. In: An invitation to reflexive sociology. The University of Chicago Press.

Wrench, A., and R. Garrett. 2015. PE: it's just me: physically active and healthy teacher bodies. International Journal of Qualitative Studies in Education 28 (1): 72-91. https://doi.org/10.1080/09518 398.2013 .855342 .

Yang, Y. 2014. Bourdieu, Practice and Change: Beyond the criticism of determinism. Educational Philosophy and Theory 46 (14): 1522-1540. https://doi.org/10.1080/00131857.2013.839375.

Publisher's Note Springer Nature remains neutral with regard to jurisdictional claims in published maps and institutional affiliations. 
Benjamin Hanckel is a sociologist at the Institute for Culture and Society at Western Sydney University. Benjamin's research interests are in youth health and wellbeing practices, social inequalities in health, digital health and social change.

Sarah Milton is a sociologist at the Social Science \& Urban Public Health Institute at King's College London. Her research interests are in ageing, family and relationship transitions, urban planning and public health, and ethnography.

Judith Green is Professor of Sociology at the Wellcome Centre for Cultures \& Environments of Health, at the University of Exeter. Her research interests are in risk, the sociology of public health, mobility and methodology. 